\title{
Fenretinide stimulates redox-sensitive ceramide production in breast cancer cells: potential role in drug-induced cytotoxicity
}

\author{
F Rehman', P Shanmugasundaram' and MP Schrey*,1 \\ 'Section of Endocrinology \& Metabolic Medicine, Imperial College London, St Mary's Hospital, Praed Street, London W2 INY, UK
}

\begin{abstract}
The synthetic retinoid N-(4-hydroxphenyl) retinamide (4HPR) has manifold actions, which may contribute to its chemopreventive effects on breast cancer cell growth and progression. A role for ceramide as a stress-response signal is investigated here during the cytotoxic action of 4HPR in MCF-7 cells. N-(4-hydroxphenyl) retinamide induced a dose-dependent decline in cell growth and survival associated with a maximal 10 -fold increase in ceramide production at $10 \mu \mathrm{M}$. N-(4-hydroxphenyl) retinamide exhibited a greater potency than all-trans retinoic acid (ATRA) on growth inhibition and ceramide production. The synthetic peroxisome proliferator-activated receptors agonist troglitazone (TGZ), but not the native ligand I5-deoxy-delta |2,|4-prostaglandin $\mathrm{J}_{2}$, abrogated both these actions of 4HPR but not that of ATRA. The antioxidant $\mathrm{N}$-acetylcysteine mimicked the abrogative effect of TGZ on 4HPR action, while the exogenous oxidant $\mathrm{H}_{2} \mathrm{O}_{2}$ also stimulated ceramide production. The inhibitors of de novo ceramide synthesis, fumonisin $B_{1}$ and myriocin, blocked the ceramide response to $4 \mathrm{HPR}$ and partially reversed the apoptotic response, but did not prevent the overall decline in cell survival. The pancaspase inhibitor Z-VAD fmk reduced the decrease in cell survival caused by $4 \mathrm{HPR}$, but did not affect the ceramide response. These findings describe a novel redox-sensitive elevation of ceramide levels associated with the cytotoxic response of breast cancer cells to 4HPR. However, a major mediatory role for this sphingolipid in this context remains equivocal.
\end{abstract}

British Journal of Cancer (2004) 91, I82I-1828. doi:I0.1038/sj.bjc.66022I2 www.bjcancer.com

Published online 26 October 2004

(c) 2004 Cancer Research UK

Keywords: 4HPR; ceramide; MCF-7

The potential application of retinoids for breast cancer prevention and treatment reflects their important role as regulators of cell growth and differentiation. Retinoids initiate many of their actions by ligand-induced dimerisation of retinoic acid receptors (RARs) and retinoid $\mathrm{X}$ receptors, followed by receptor binding to retinoid response elements on DNA and transactivation of retinoidresponse target genes. All-trans retinoic acid (ATRA), the most potent naturally occurring metabolite of vitamin A, reversibly inhibits the growth of hormone-dependent human breast cancer cells, requiring the activation of RAR $\alpha$-mediated gene transcription for this effect (Dawson et al, 1995). Synthetic modification of the carboxyl end of retinoic acid with an $\mathrm{N}-4$ hydroxyphenyl group results in the formation of $\mathrm{N}$-4-(hydroxyphenyl) retinamide (4HPR) or fenretinide. $\mathrm{N}$-4-(hydroxyphenyl) retinamide is more potent than ATRA, both as an antiproliferative agent and inducer of apoptosis in the majority of cancer cell lines tested (Oridate et al, 1996; Zou et al, 1998). Compared with ATRA, 4HPR exhibits reduced hepatotoxicity and increased efficacy in inhibiting mammary carcinogenesis in animal models (Ulukaya and Wood, 1999). Recent clinical studies also highlight a potential chemopreventative action of $4 \mathrm{HPR}$ on breast cancer recurrence in high-risk premenopausal women (Veronesi et al, 1999; Decensi et al, 2000).

Although 4HPR can transactivate certain retinoid receptors and RAR antagonists can partially block $4 \mathrm{HPR}$-induced apoptosis (Sun

*Correspondence: Dr MP Schrey; E-mail: m.schrey@imperial.ac.uk We wish to dedicate this work to the memory of Rosie Schrey Received 2 April 2004; revised 23 August 2004; accepted 13 September 2004; published online 26 October 2004 et al, 1999) compared with ATRA, 4HPR binds with low affinity to RAR and demonstrates poor transactivation of RAR/RXR response elements in human breast cancer cells (Sheikh et al, 1995). Retinoid receptors can also interact with peroxisome proliferatoractivated receptors (PPARs) either directly through the formation of heterodimers (Schulman et al, 1998) or indirectly by regulating their mutual expression (Stoll, 2002; James et al, 2003). In this regard, when combined with $\operatorname{PPAR} \gamma$ agonists such as troglitazone (TGZ), ATRA synergistically and irreversibly inhibits growth and induces apoptosis in human breast cancer cells (Elstner et al, 1998). Whether PPAR $\gamma$ agonists manifest similar interactions with $4 \mathrm{HPR}$ in breast cancer cells is unknown.

As well as activating receptor-mediated mechanisms, retinoids such as 4 HPR may modulate cell function via alternative receptorindependent pathways involving cellular signals such as reactive oxygen species (ROS) (Sun et al, 1999) and the sphingolipid ceramide (DiPietrantonio et al, 1998).

Evidence supporting a role for ceramide during $4 \mathrm{HPR}$ action on HL-60 leukaemia cells and neuroblastoma cells is based on studies demonstrating an elevation of cellular ceramide levels in response to $4 \mathrm{HPR}$ and the ability of the ceramide synthase inhibitor fumonisin $\mathrm{B}_{1}\left(\mathrm{FB}_{1}\right)$ to block this ceramide response and prevent 4HPR-induced apoptosis (DiPietrantonio et al, 1998; Maurer et al, 1999). However, in other instances where induction of apoptosis is accompanied by an elevation of ceramide, $\mathrm{FB}_{1}$ failed to prevent the apoptotic response while blocking ceramide production (Nagy et al, 2000; Miguet et al, 2001).

Several studies have also demonstrated a role for ROS during the induction of apoptosis by $4 \mathrm{HPR}$ in various cell types (Sun et al, 
1999; Suzuki et al, 1999). Furthermore, cellular redox status and ROS are also known to regulate critical steps in a wide variety of cellular functions including sphingolipid pathways involved in stress-response signalling (Andrieu-Abadie et al, 2001). The nature and relevance of ceramide production and signalling, and its relationship to redox status during $4 \mathrm{HPR}$ action in human breast cancer cells, are unknown.

A better understanding of the molecular mechanisms involved in the cytotoxic actions of anticancer agents such as 4HPR is crucial for the further development and chemotherapeutic use of such drugs. In the present study with the human breast cancer cell line MCF-7, we have compared the effects and interactions of both native and synthetic retinoids (ATRA and 4HPR) and PPAR $\gamma$ agonists (15-deoxy-delta 12,14-prostaglandin $\mathrm{J}_{2}, 15 \mathrm{~d}-\mathrm{PGJ}_{2}$ and TGZ) on cell growth, survival and ceramide production. Under a variety of conditions, retinoid action on cell growth, survival and cytotoxicity was associated with corresponding changes in ceramide production. $\mathrm{N}$-(4-hydroxphenyl) retinamide exhibited much greater potency and efficacy than ATRA on inhibiting cell growth and inducing ceramide production and cytotoxicity. Troglitazone, but not $15 \mathrm{~d}-\mathrm{PGJ}_{2}$, blocked the antiproliferative and cytotoxic actions of $4 \mathrm{HPR}$ and reduced the ceramide response, possibly as a consequence of its antioxidant properties. Although $\mathrm{FB}_{1}$ prevented the ceramide response to $4 \mathrm{HPR}$, the decline in cell survival was unaffected.

\section{MATERIALS AND METHODS}

\section{Materials}

Unless otherwise stated, all sphingolipid standard chemicals, reagents and materials for cell culture were purchased from Sigma (Poole, Dorset, UK). Culture media and supplements were obtained from ICN Biochemicals (High Wycombe, UK). 15-deoxydelta 12,14-prostaglandin $\mathrm{J}_{2}$ was obtained from Affiniti Research Products (Exeter, UK), TGZ was a gift from Glaxo Wellcome (Uxbridge, UK) and SDZ PSC 833 was a gift from Novartis Pharma AG (Basel, Switzerland).

\section{Cell culture}

MCF-7 cells were obtained from the European Collection of Animal Cell Cultures (Salisbury, UK) and maintained at $37^{\circ} \mathrm{C}$ in Eagle's minimal essential medium (EMEM) supplemented with glutamine $(2 \mu \mathrm{M})$, nonessential amino acids and $10 \%$ foetal calf serum. For all experiments monitoring cell growth, apoptosis and ceramide production cell stocks grown in $25 \mathrm{~cm}^{2}$ flasks were trypsinised and seeded into six-well plates in supplemented EMEM containing penicillin $\left(100 \mathrm{U} \mathrm{ml}^{-1}\right)$, streptomycin $\left(100 \mu \mathrm{g} \mathrm{ml}^{-1}\right)$ and amphotericin- $\beta\left(250 \mathrm{ng} \mathrm{ml}^{-1}\right)$.

\section{Cell growth}

The effects of various treatments (see legends for details) on MCF7 cell growth were monitored over a $72 \mathrm{~h}$ period. Trypsinised cells were seeded into six-well plates and allowed to plate down for $18 \mathrm{~h}$ prior to addition of treatments. Cell numbers were determined at the end of the growth period by counting isolated cell nuclei by the Coulter principle following treatment of intact cells with Zaponin (Coulter, Luton, UK).

\section{Cell survival}

The effects of various treatments on MCF-7 cell survival was monitored after a $72 \mathrm{~h}$ incubation period using the Promega MTS assay (Madison, WI, USA) as an index of cell viability. The tetrazolium compound MTS is bioreduced by cells into a coloured formazan product that absorbs light at $490 \mathrm{~nm}$. Absorbance is proportional to the number of viable cells present. Trypsinised cells were diluted to a concentration of $10^{5}$ cells ml ${ }^{-1}$ and $50 \mu \mathrm{l}$ aliquots were seeded into 96 -well plates $\left(5000\right.$ cells well $\left.^{-1}\right)$. After a $6 \mathrm{~h}$ plating period, various treatments were added in $50 \mu \mathrm{l}$ and the cells incubated for a further $72 \mathrm{~h}$ in EMEM containing supplements. After this incubation, $20 \mu \mathrm{l}$ of MTS assay reagent was added and absorbance measured at $490 \mathrm{~nm}$ after $90 \mathrm{~min}$ of colour development. After subtracting the background absorbance of cell-free incubations, cell survival was determined by expressing all values as a percentage of control absorbance measured in the absence of treatment.

\section{DNA fragmentation ELISA}

This photometric enzyme-immunoassay measures cytoplasmic histone-associated DNA fragments (mono- and oligonucleosomes), which are generated during apoptosis (Roche Applied Science). The enrichment of nucleosomes in the cytoplasm of treated cells is expressed as a fold induction of apoptosis compared to untreated controls. Assay samples were prepared according to the manufacturer's instructions (Roche Applied Science, Mannheim, Germany). MCF-7 cells were seeded in supplemented EMEM into 96-well plates at $10^{4}$ cells well ${ }^{-1}$. After $18 \mathrm{~h}$, treatments were added (see legend Figure 6 for details) and the cells incubated for a further $24 \mathrm{~h}$. The medium was then removed and cell lysates were prepared and centrifuged for $10 \mathrm{~min}$ at $200 \mathrm{~g}$. A measure of $20 \mu \mathrm{l}$ aliquots of the supernatant (cytoplasmic fraction) was then assayed for nucleosome content by ELISA in accordance with the manufacturer's protocol.

\section{Sphingolipid metabolism}

Ceramide and glucosylceramide were measured by radiolabelled incorporation of $\left[{ }^{3} \mathrm{H}\right]$ palmitic acid into the appropriate sphingolipids, as described previously (Cabot et al, 1998). MCF-7 cells were grown to approximately $70 \%$ confluence in six-well plates in $2 \mathrm{ml}$ of supplemented EMEM. At this point, the fresh medium was added containing the various treatments (see legends for details) and $\left[{ }^{3} \mathrm{H}\right]$ palmitic acid $\left(1 \mu \mathrm{Ci} \mathrm{ml}^{-1}\right)$ (Amersham, UK). The cells were then incubated for a further $24 \mathrm{~h}$. Experiments were terminated by the removal of the medium and addition of $2 \mathrm{ml}$ acidified methanol (2\% acetic acid). Any non-adherent cells were retrieved by centrifugation. Cellular lipids were allowed to be extracted into the methanol over a $30 \mathrm{~min}$ period at room temperature. This methanol extract was removed to glass tubes and the lipids extracted into a chloroform phase following addition and mixing with $2 \mathrm{ml}$ chloroform and $2 \mathrm{ml}$ of KCl/EDTA ( $2 \mathrm{M} /$ $5 \mathrm{~mm}$ ). Total cellular radiolabelled lipid was measured by counting a $100 \mu \mathrm{l}$ aliquot of this chloroform extract following solvent evaporation. The ceramide standard containing primarily stearic and nervonic species $\left(\mathrm{C}_{18}\right.$ and $\left.\mathrm{C}_{24}\right)$ was added to a $1 \mathrm{ml}$ aliquot of each lipid extract sample to act both a carrier and marker. These ceramide species were separated from the remaining lipids by TLC in the solvent system chloroform/acetic acid $\left(90: 10, \mathrm{v} \mathrm{v}^{-1}\right) . \mathrm{C}_{18}$ and $\mathrm{C}_{24}$ ceramide were also resolved from one another in this system with $\mathrm{Rf}$ values of 0.29 and 0.38 , respectively. However, this system does not resolve the biologically inactive dihydroceramides. Glucosylceramide was resolved from other lipids by TLC in the solvent system chloroform/methanol/ammonia $\left(70: 20: 4, \mathrm{vv}^{-1}\right)$ also using appropriate commercial standards, as described above. Resolved lipid bands were visualised by staining with iodine vapour, scraped into scintillation vials containing $0.5 \mathrm{ml}$ water and $10 \mathrm{ml}$ ECOSCINT, and radioactivity measured by liquid scintillation counting. The majority of $\left[{ }^{3} \mathrm{H}\right]$ palmitic acid incorporated into cellular lipids was present as phospholipid esters. These polar lipids remained at the origin in the solvent systems used and in no instances where changes in ceramide production were observed in response to $4 \mathrm{HPR}$, were there significant accompanying changes in 
total phospholipid. Similarly, no significant changes in total cellular lipids were observed in response to any experimental treatments. Values for radiolabelled incorporation into ceramide and glucosylceramide are expressed as a percentage of total cellular lipid. Such 'normalisation' of the data will compensate for any skewness in the data, which would occur if any treatments also affected general permissive lipid pathways such as fatty acid uptake or CoA ester formation. Similarly, elongation, desaturation or recycling may occur in certain $\left[{ }^{3} \mathrm{H}\right]$ palmitate pools in response to treatments, which could slightly skew the results obtained only if the resulting palmitate metabolites are selectively or preferentially incorporated by ceramide-producing pathways.

Temporal changes in sphingomyelin levels and ceramide production were also monitored in MCF-7 cells prelabelled to steady-state levels with $\left[{ }^{3} \mathrm{H}\right]$ palmitic acid $\left(1 \mu \mathrm{Ciml}{ }^{-1}\right)$ for $24 \mathrm{~h}$. Sphingomyelin was resolved from total cellular lipids by TLC in the solvent system chloroform/methanol/acetic acid/water $\left(50: 30: 7: 4, \mathrm{vv}^{-1}\right)$.

\section{Expression of data and statistical analysis}

Unless otherwise stated, all values are presented as the mean \pm s.d. from individual representative experiments each carried out in triplicate on two or more occasions. Statistical significance of differences between experimental groups was determined by analysis of variance followed by unpaired Student's $t$-test.

\section{RESULTS}

\section{Differential action of 4HPR, ATRA and PPAR $\gamma$ agonists on cell growth morphology and survival}

The RAR agonist ATRA $(5 \mu \mathrm{M})$ reduced MCF-7 cell growth by around $50 \%$ after $72 \mathrm{~h}$, whereas $4 \mathrm{HPR}(5 \mu \mathrm{M})$ prevented any net cell growth during this period (Figure 1A). The synthetic PPAR $\gamma$ agonist TGZ blocked this action of $4 \mathrm{HPR}$ but had no effect on ATRA-induced growth inhibition (Figure 1A). In contrast, the putative PPAR $\gamma$ agonist $15 \mathrm{~d}-\mathrm{PGJ}_{2}$ had no effect on $4 \mathrm{HPR}$ action (Figure 1B), suggesting that the interaction of TGZ and 4HPR may be PPAR $\gamma$-independent. $N$-(4-hydroxphenyl) retinamide also induced a 'cytotoxic morphology' with increased cell rounding, vacuolation and detachment, and this action was also blocked by TGZ (Figure 2). Neither ATRA nor TGZ alone had any significant effect on cell morphology (unpublished observations). Since ROS have been implicated during $4 \mathrm{HPR}$-induced cytotoxicity and TGZ may possess free radical scavenging properties due to its $\alpha$-tocopherol moiety, the effects of the antioxidants $\alpha$-tocopherol and $N$-acetylcysteine on $4 \mathrm{HPR}$ action were also investigated. Both $\alpha$-tocopherol $(10 \mu \mathrm{M})$ and $N$-acetylcysteine $(10 \mathrm{mM})$ partially reversed the inhibitory action of $4 \mathrm{HPR}$ on cell growth by $34 \pm 3$ and $45 \pm 5 \%$, respectively $(P<0.01, n=3)$ in addition to reducing the $4 \mathrm{HPR}$-induced cytotoxic morphology (unpublished observations).

\section{$N$-(4-hydroxphenyl) retinamide stimulates redox-sensitive ceramide production}

The dose-dependent decrease in cell survival after $72 \mathrm{~h}$ in response to $4 \mathrm{HPR}$ was mirrored by a preceding increase in ceramide production after $24 \mathrm{~h}$ (Figure $3 \mathrm{~A}$ ). Consistent with previous studies, 4HPR also induced an apparent $266 \%$ increase in apoptosis as measured by the enrichment of cytosolic nucleosomes after $24 \mathrm{~h}$ (see Figure 6). Sphingomyelin hydrolysis has been identified as a mechanism responsible for agonist-induced ceramide production in a number of studies. In MCF-7 cells prelabelled to steady-state levels with $\left[{ }^{3} \mathrm{H}\right]$ palmitate, no significant changes in sphingomyelin levels were detected in response to $4 \mathrm{HPR}$ over a $24 \mathrm{~h}$ incubation and no major early changes in
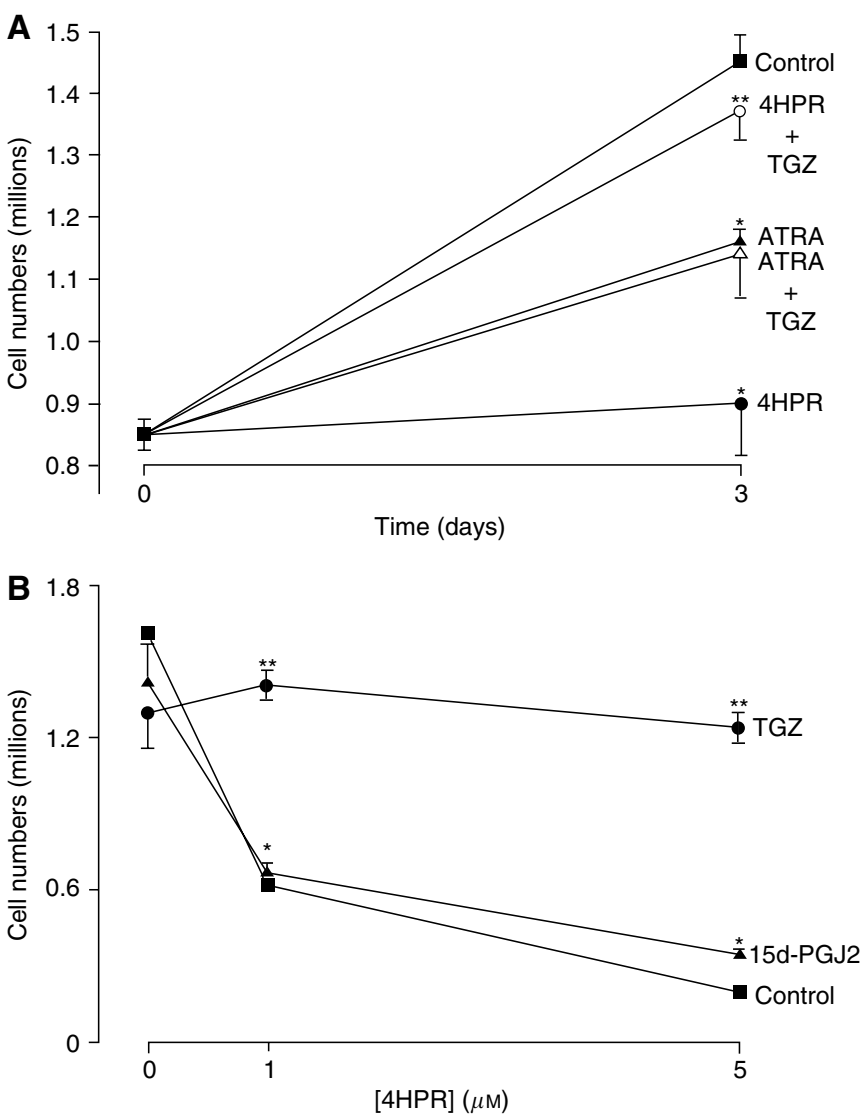

Figure I Effect of retinoids and PPAR $\gamma$ agonists on breast cancer cell growth. MCF-7 cells were grown over a 3-day period: $(\mathbf{A})$ in the presence or absence of $4 \mathrm{HPR}, 5 \mu \mathrm{M}$; TGZ, $5 \mu \mathrm{M}$; or ATRA, $5 \mu \mathrm{M}$ or $(\mathbf{B})$ in the presence or absence of 4HPR; TGZ, $5 \mu \mathrm{M}$; or $\left(5 \mathrm{~d}-\mathrm{PG}_{2}\right), 5 \mu \mathrm{M}$. Cell nuclei were harvested and counted as described (see Materials and Methods). (A) ${ }^{*} P<0.02$ for inhibition vs control; $* * P<0.02$ for reversal of $4 \mathrm{HPR}$ induced growth inhibition by TGZ. (B) $* P<0.01$ for inhibition vs control values in the absence of 4HPR; $* * P<0.02$ for reversal of $4 \mathrm{HPR}$-induced inhibition by TGZ.

ceramide production were detected before $24 \mathrm{~h}$ (Figure 3B). In contrast to the 3.7-fold increase in cellular ceramide levels observed in response to 4HPR $(5 \mu \mathrm{M})$, ATRA $(5 \mu \mathrm{M})$ elicited a relatively modest $40 \%$ increase in ceramide (Figure $4 \mathrm{~A}$ ).

As seen with the effects of $4 \mathrm{HPR}$ on cell growth and morphology, TGZ also reduced the ceramide response to $4 \mathrm{HPR}$ (Figure $4 \mathrm{~B}$ ) as did the antioxidant $\mathrm{N}$-acetylcysteine (Figure 4B). The addition of exogenous oxidant in the form of $\mathrm{H}_{2} \mathrm{O}_{2}$ mimicked the stimulatory effect of $4 \mathrm{HPR}$ on ceramide production and similarly, $\mathrm{N}$-acetylcysteine also reduced this ceramide response (Figure 4B).

\section{Effect of putative ceramide modulators on 4HPR action}

To further investigate a potential mediatory role for ceramide during 4HPR action, we determined the effects of ceramide synthase activators and inhibitors and glucosylceramide synthase inhibition. The amide-linked fatty acid constituents of mammalian ceramides have acyl chains of varying lengths from 16-24 carbon atoms $\left(\mathrm{C}_{16}-\mathrm{C}_{24}\right)$. The physiological significance of these different ceramide species in terms of metabolic function or origin is unknown. The putative 'activator' of de novo ceramide synthesis, PSC 833, stimulated the incorporation of $\left[{ }^{3} \mathrm{H}\right]$ palmitate into both $\mathrm{C}_{18}$ and $\mathrm{C}_{24}$ ceramide species to similar levels (Table 1). In 


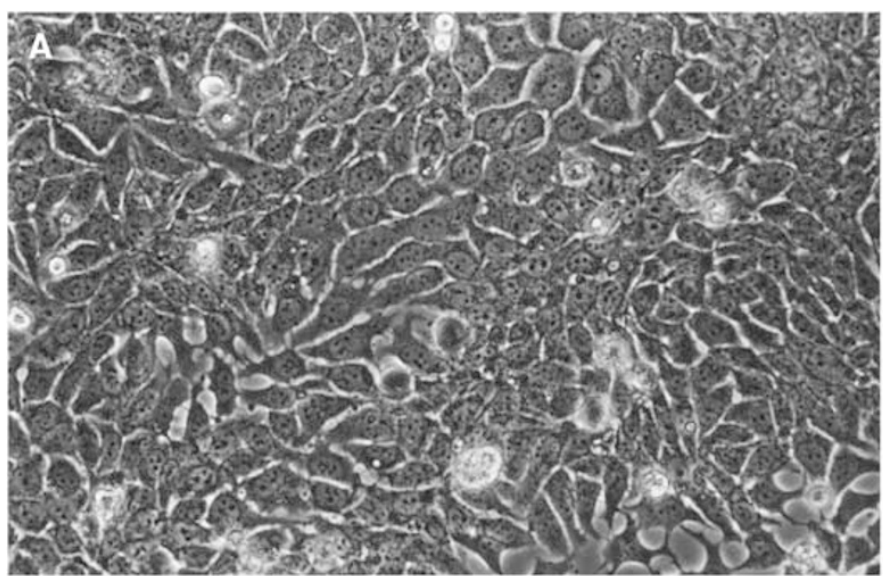

Control

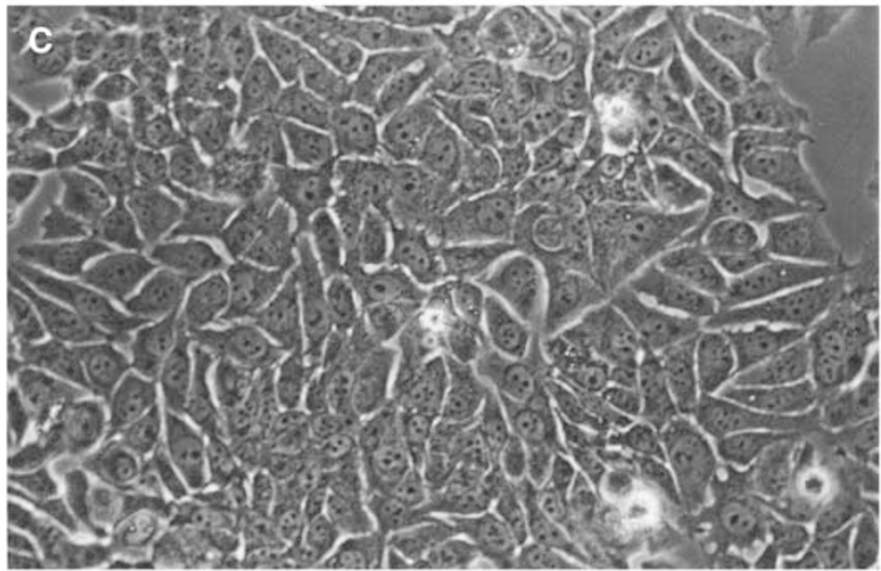

TGZ

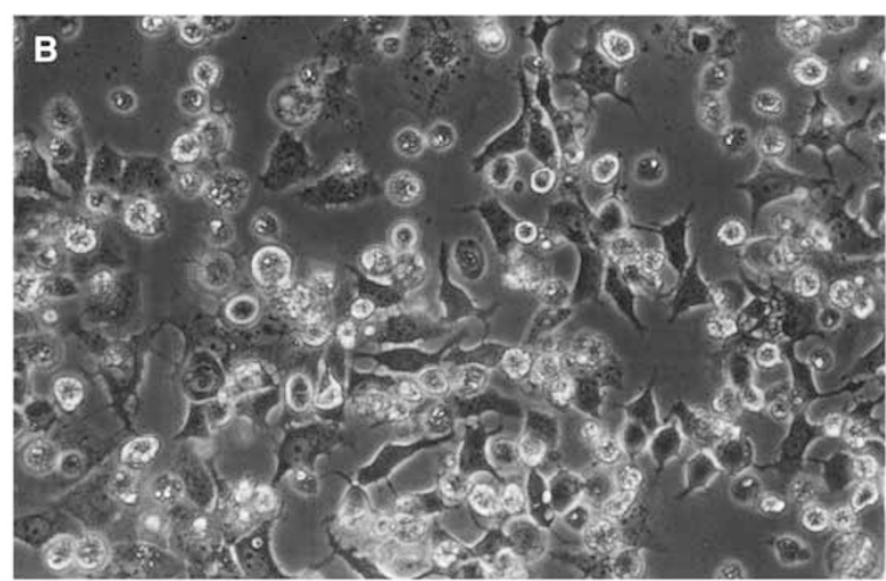

4HPR

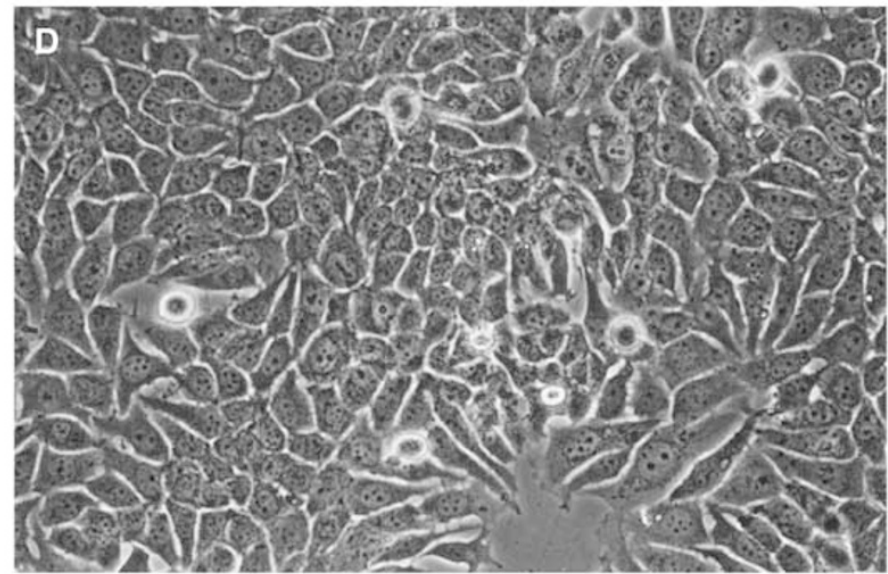

$4 \mathrm{HPR}+\mathrm{TGZ}$

Figure 2 Effect of 4HPR and TGZ on MCF-7 cell morphology. Cells were grown over a 3-day period in the presence or absence of 4HPR, $5 \mu \mathrm{M}$ and/or TGZ, $5 \mu \mathrm{M}$ : (A) control;(B) 4HPR $5 \mu \mathrm{M}$; (C) TGZ; (D) 4HPR and TGZ. Note cell rounding and detachment along with cytoplasmic vacuolation in the presence of 4HPR (B). TGZ blocked this 4HPR-induced cytotoxic morphology (D).

contrast, 4HPR caused a much greater (3.3-fold) accumulation of $\mathrm{C}_{24}$ vs $\mathrm{C}_{18}$ ceramide, an action which was associated with a more potent cytotoxic response to $4 \mathrm{HPR}$ (Table 1). These differential actions of 4HPR and PSC 833 are not in keeping with a common mechanism of enhanced ceramide accumulation in response to these agents. Indeed, such differential effects on ceramide molecular species may also reflect a differential action of $4 \mathrm{HPR}$ and PSC 833 on palmitate metabolism. The observed effect of PSC 833 in MCF-7 cells is consistent with previous studies (Cabot et al, 1998) and lends further support for a mediatory role for endogenous ceramide in the control of cell death.

Recent studies have reported an increased ability of drugresistant cells to scavenge ceramide via enhanced glycosylation, thereby minimising ceramide-induced apoptotic death (Lavie et al, 1996; Nicholson et al, 1999). Hence, manipulation of this pathway may modulate chemotoxicity in cancer cells. The effect of the glucosylceramide synthase inhibitor (D,-L,-threo)-1-phenyl-2-decanoylamino-3-morpholino-1-propanol (PDMP) on 4HPR action is shown in Table 2. (D,-L,-threo)-1-phenyl-2-decanoylamino-3morpholino-1-propanol clearly enhanced the 4HPR-induced decline in cell survival, in addition to reducing glucosylceramide levels by nearly 70\% (Table 2). However, the degree of 4HPRinduced ceramide accumulation remained unaltered in the presence of PDMP (Table 2). Furthermore, in contrast to the three-fold increase in ceramide in response to $4 \mathrm{HPR}$, basal glucosylceramide levels remained unaffected by the retinoid (Table 2).

The ceramide synthase inhibitor $\mathrm{FB}_{1}$ reduced the $4 \mathrm{HPR}$-induced ceramide response by around $90 \%$ (Figure $5 \mathrm{~A}$ ). In contrast, the decline in cell survival after 3 days in the presence of $4 \mathrm{HPR}$ was unaffected by $\mathrm{FB}_{1}$ (Figure $5 \mathrm{~B}$ ). Similarly, $\mathrm{FB}_{1}$ did not prevent the 4HPR-induced cytotoxic morphology (unpublished observations). Although $\mathrm{FB}_{1}$ alone did not affect the overall cell survival in control cells after 3 days (Figure 5B), the incorporation of $\left[{ }^{3} \mathrm{H}\right]$ palmitate into ceramide was reduced by around $67 \%$ (Figure 5A), and apoptosis was increased two-fold after $24 \mathrm{~h}$ (Figure 6). In relation to respective control values, the apoptotic response to $4 \mathrm{HPR}(266 \%)$ was reduced to $131 \%$ in the presence of $\mathrm{FB}_{1}$ (Figure 6). Similarly, inhibition of serine palmitoyl transferase, the initial rate-limiting step in ceramide synthesis, by myriocin, which inhibited ceramide synthesis by more than $90 \%$ (unpublished observations), also reduced the apparent apoptotic response to $4 \mathrm{HPR}$ in addition to inducing apoptosis in the absence of $4 \mathrm{HPR}$ (Figure 6). The pancaspase inhibitor Z-VAD fmk partially reversed (by approximately 70\%) the decline in cell survival due to $4 \mathrm{HPR}$ (Figure 5B), but had no effect on the ceramide response to $4 \mathrm{HPR}$ (Figure 5A). In addition to supporting a role for caspases during 4HPR-induced cell death, these observations indicate that ceramide production in response to $4 \mathrm{HPR}$ is upstream or independent of caspase activation. 

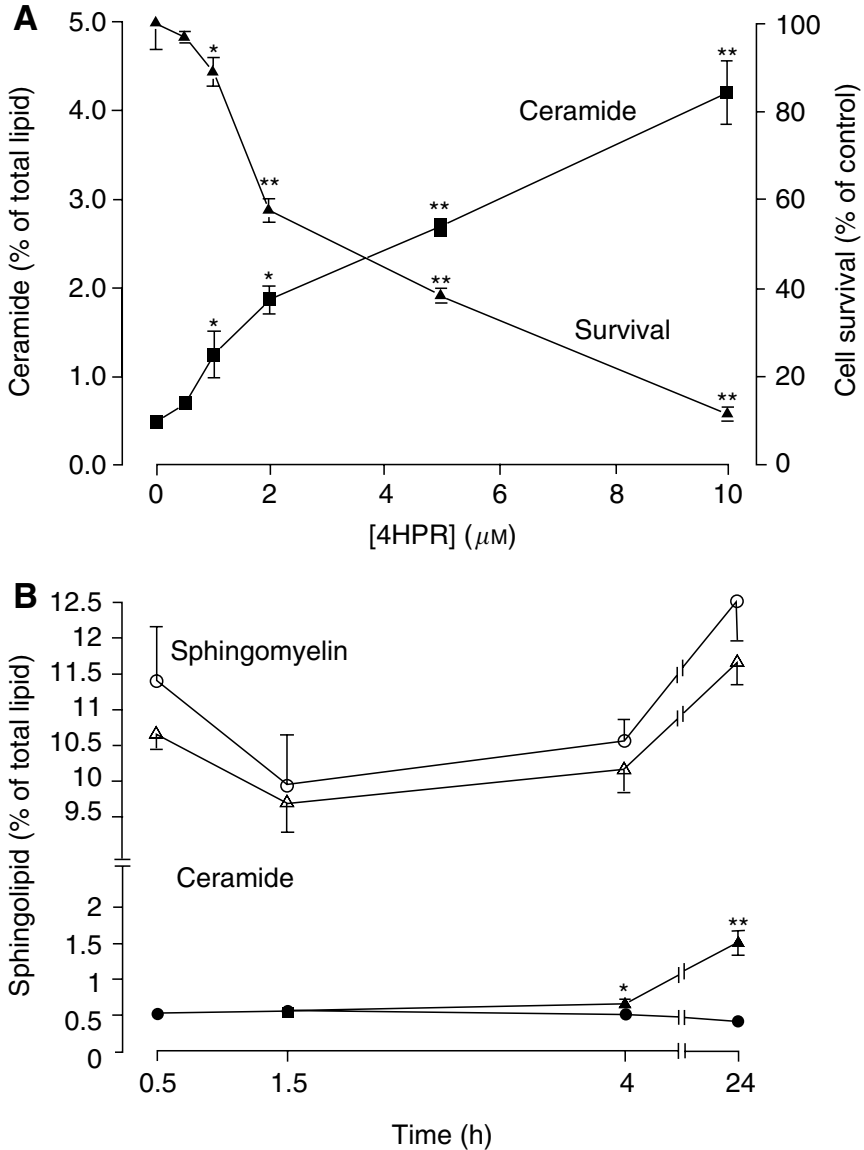

Figure 3 Effect of 4HPR on sphingolipid metabolism and cell survival. (A) Cells were grown over a 3-day period in the presence or absence of $4 \mathrm{HPR}$. Cell survival at the end of this time was assessed by the MTS assay as an index of cell viability (see Materials and Methods). Total ceramide production was measured after $24 \mathrm{~h}$ as determined by the incorporation of $\left[{ }^{3} \mathrm{H}\right]$ palmitic acid into both ceramide species $\left(C_{18}\right.$ and $\left.C_{24}\right)$. Radiolabelled ceramide is expressed as a percentage of total ${ }^{3} \mathrm{H}$-labelled cellular lipid, which remained unchanged in response to 4HPR (see Materials and Methods). (B) Sphingomyelin levels (open symbols) and ceramide production (closed symbols) were monitored over a $24 \mathrm{~h}$ period in the presence (triangles) or absence (circles) of 4HPR ( $10 \mu \mathrm{M})$ in cells previously prelabelled to steadystate levels with $\left.{ }^{3} \mathrm{H}\right]$ palmitate (see Methods and Materials). ${ }^{*} P<0.05$; ** $P<0.0$ I for significant changes in the presence of $4 \mathrm{HPR}$.

Table I Effect of 4HPR and PSC 833 on ceramide composition and survival in MCF-7 cells

\section{Ceramide composition \% of total lipid}

\begin{tabular}{lccc}
\cline { 2 - 3 } Treatment & $\mathbf{C}_{\mathbf{1 8}}$ & $\mathbf{C}_{\mathbf{2 4}}$ & $\begin{array}{c}\text { Cell survival \% } \\
\text { of control }\end{array}$ \\
\hline Control & $0.21 \pm 0.02$ & $0.12 \pm 0.02$ & $100 \pm 5$ \\
$4 \mathrm{HPR}$ & $0.53 \pm 0.05^{*}$ & $1.77 \pm 0.20^{*}$ & $18 \pm 2 *$ \\
PSC 833 & $0.82 \pm 0.11^{*}$ & $0.81 \pm 0.02 *$ & $29 \pm 3^{*}$ \\
\hline
\end{tabular}

$4 \mathrm{HPR}=\mathrm{N}$-(4-hydroxphenyl) retinamide. Ceramide production was measured after $24 \mathrm{~h}$ incubation of MCF-7 cells in medium containing $\left[{ }^{3} \mathrm{H}\right.$ ]palmitic acid in the absence or presence of 4HPR $(10 \mu \mathrm{M})$ or PSC $833(10 \mu \mathrm{M})$. Incorporation of radiolabelled precursor into the ceramide species $C_{18}$ and $C_{24}$ was determined following lipid extraction and TLC. No significant changes in total cellular ${ }^{3} \mathrm{H}$-labelled lipid were observed in response to any of the treatments, the respective values for control, $4 \mathrm{HPR}$ and PSC 833 being 44835 $\pm 2004,40816 \pm 2092$ and $46684 \pm 2995$ c.p.m. incubation ${ }^{-1}$. Cell survival was measured in separate incubations as described (see Materials and Methods). $* P<0.01$ for significance vs control values.
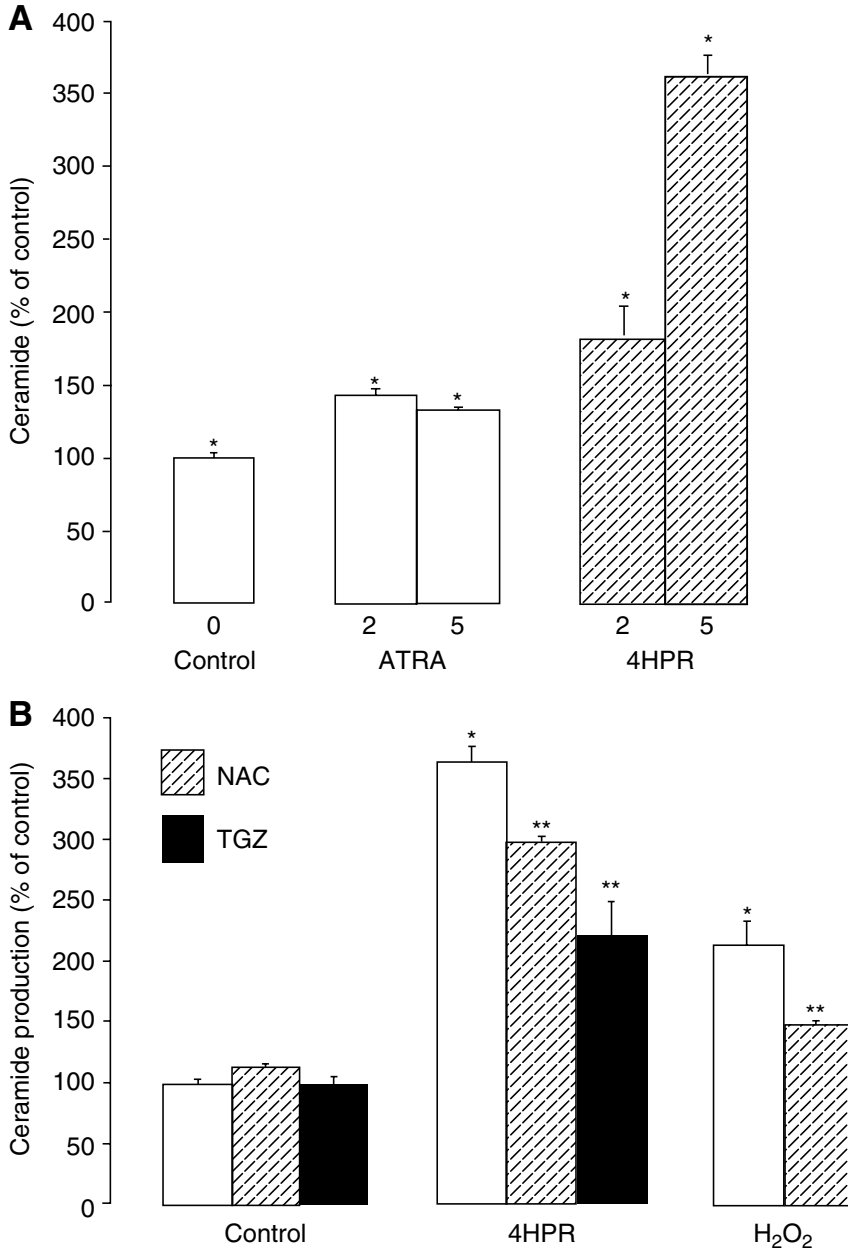

Figure 4 Effect of ATRA, 4HPR and redox modulators on ceramide production. MCF-7 cells were grown to approximately $70 \%$ confluence and ceramide production was measured (see Materials and Methods) during a subsequent $24 \mathrm{~h}$ period: (A) in the absence or presence of ATRA $(2,5 \mu \mathrm{M})$ or $4 \mathrm{HPR}(2,5 \mu \mathrm{M}) ;(\mathbf{B})$ in the absence or presence of $5 \mu \mathrm{M} 4 \mathrm{HPR}, 0.5 \mathrm{mM}$ $\mathrm{H}_{2} \mathrm{O}_{2}, 10 \mathrm{mM} \mathrm{N}$-acetylcysteine (NAC) or $5 \mu \mathrm{M}$ TGZ. Total ceramide production is expressed as a percentage of control values determined in the absence of 4HPR. Control ceramide levels were calculated to be $0.53 \pm 0.04 \%$ of total ${ }^{3} \mathrm{H}$-labelled lipid. $(\mathbf{A}) * P<0.02$ for stimulation; (B) $* P<0.02$ for stimulation; $* * P<0.05$ for reduction of this stimulation.

Table 2 Effect of 4HPR and PDMP on sphingolipid metabolism and survival in MCF-7 cells

\section{Sphingolipid levels \% of total lipid}

\begin{tabular}{llcc}
\cline { 2 - 3 } Treatment & Ceramide & Glucosylceramide & $\begin{array}{c}\text { Cell survival \% } \\
\text { of control }\end{array}$ \\
\hline Control & $0.45 \pm 0.04$ & $1.42 \pm 0.09$ & $100 \pm 3$ \\
$4 \mathrm{HPR}$ & $1.45 \pm 0.43^{*}$ & $1.36 \pm 0.07$ & $69 \pm 2 *$ \\
PDMP & $0.52 \pm 0.04$ & $0.46 \pm 0.07 *$ & $90 \pm 5^{*}$ \\
$4 \mathrm{HPR}+\mathrm{PDMP}$ & $1.41 \pm 0.22^{*}$ & $0.44 \pm 0.01 *$ & $27 \pm 2 *$ \\
\hline
\end{tabular}

$4 \mathrm{HPR}=\mathrm{N}$-(4-hydroxphenyl) retinamide. PDMP $=(\mathrm{D},-\mathrm{L},-$ threo $)-\mathrm{I}$-pheny $\mid$-2-decanoylamino-3-morpholino-I-propanol. Incorporation of $\left.{ }^{3} \mathrm{H}\right]$ palmitic acid into cellular ceramide and glucosylceramide was measured following incubation of MCF-7 cells in the presence or absence of 4HPR $(5 \mu \mathrm{M})$, PDMP $(20 \mu \mathrm{M})$ and 4HPR+PDMP as described (see Materials and Methods). No significant changes in total cellular ${ }^{3} \mathrm{H}$ labelled lipid were observed in response to any of the treatments. Cell survival was measured in separate incubations as described (see Materials and Methods). $* P<0.02$ for significance vs control values. 

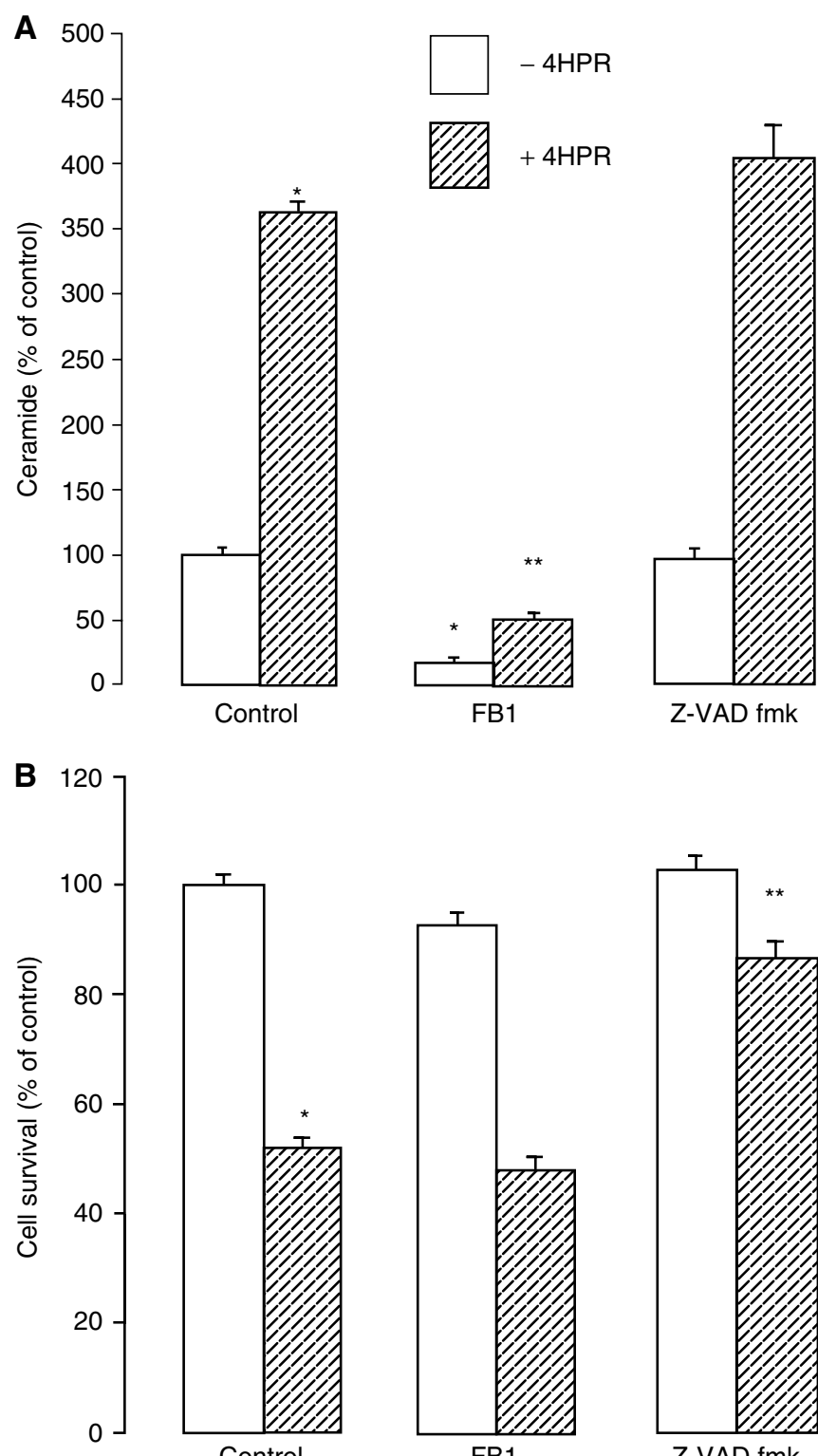

Control

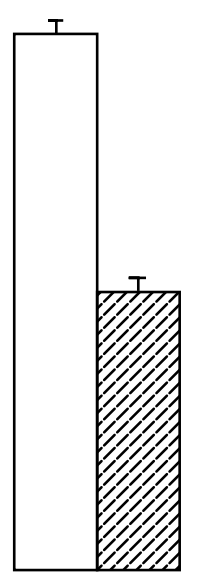

FB1

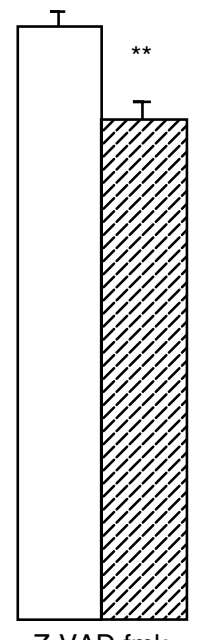

Z-VAD fmk

Figure 5 Effects of $\mathrm{FB}_{1}$ and caspase inhibition on 4HPR action. MCF-7 cells were grown over a 3-day period in the absence (open bars) or presence (hatched bars) of 4HPR $(5 \mu \mathrm{M})$, and in the absence or presence of $\mathrm{FB}_{1}(25 \mu \mathrm{M})$ or Z-VAD fmK $(50 \mu \mathrm{M})$. (A) ceramide production was measured after $24 \mathrm{~h}$ by incorporation of $\left[{ }^{3} \mathrm{H}\right]$ palmitic acid (see Materials and Methods). (B) cell survival was measured after $72 \mathrm{~h}$ by the MTS assay (see Materials and Methods). ${ }^{*} P<0.0$ I for significant changes vs control values measured in the absence of $4 \mathrm{HPR}$; $* * P<0.02$ for significant changes vs control values measured in the presence of $4 \mathrm{HPR}$.

\section{DISCUSSION}

The efficacy of 4-HPR as a chemopreventive agent in premenopausal breast cancer is exemplified by a recent phase III clinical trial, which indicates a reduction both in local recurrence and incidence of contralateral disease in response to treatment (Veronesi et al, 1999; Decensi et al, 2000). Elucidating the molecular mechanisms involved in this action will be important for the future development and improvement of therapies employing this retinoid in breast cancer treatment.

In agreement with previous studies (Sheikh et al, 1995), 4-HPR exhibited a more potent antiproliferative response compared with the native retinoid ATRA, consistent with an additional role for

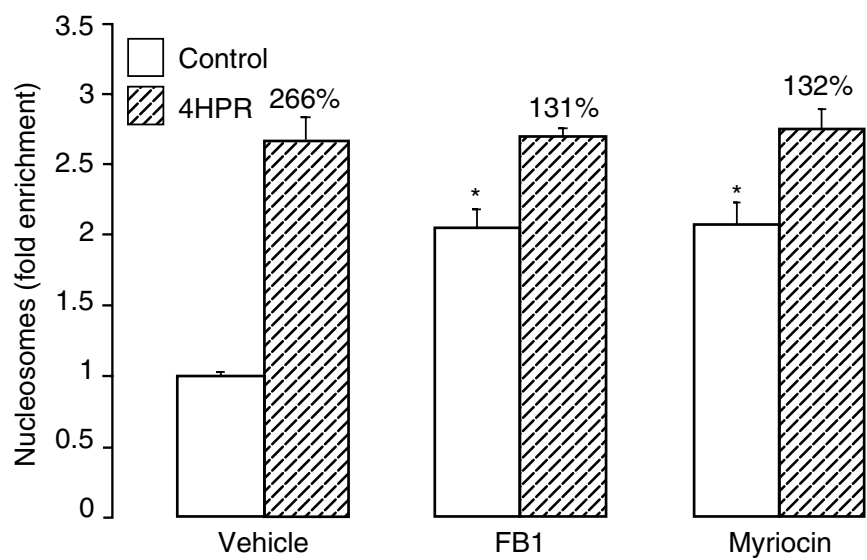

Figure 6 Effects of $4 \mathrm{HPR}, \mathrm{FB}_{1}$ and myriocin on apoptosis in MCF-7 cells. Cells were pretreated for I $\mathrm{h}$ with or without $\mathrm{FB}_{1}(25 \mu \mathrm{M})$, myriocin $(10 \mu \mathrm{M})$ or dimethylsulphoxide vehicle (0.5\%), and then incubated for a further $24 \mathrm{~h}$ in the presence (hatched bar) or absence (open bars) of 4HPR $(5 \mu \mathrm{M})$. Apoptosis was determined by ELISA of cytoplasmic DNA-histone complexes and expressed as fold enrichment of nucleosomes compared with untreated controls (see Materials and Methods). Percentage values represent the relative increase in 4HPR-induced apoptosis in the absence or presence of $\mathrm{FB}_{1}$ or myriocin. $* P<0.02$ for significant changes vs control values.

receptor-independent pathways in the action of this synthetic retinoid. In combination with $\mathrm{PPAR} \gamma$ agonists, retinoids have been reported to enhance growth inhibition and cell death in human breast cancer cell lines in vitro (Elstner et al, 1998), possibly via interactive heterodimerisation of retinoid receptors and $\operatorname{PPAR} \gamma$. In contrast, we have observed no such synergism on growth inhibition of MCF-7 cells between ATRA and the synthetic PPAR $\gamma$ agonist TGZ. Indeed, on the contrary, the antiproliferative action of 4-HPR and induction of a cytotoxic morphology were both completely blocked in the presence of TGZ. Furthermore, the putative native $\operatorname{PPAR} \gamma$ ligand $15 \mathrm{~d}-\mathrm{PGJ}_{2}$ did not mimic the abrogative action of TGZ, again suggesting a role for receptorindependent interactive mechanisms during the combined actions of 4-HPR and TGZ. This is further supported by the antagonism of 4-HPR-induced growth inhibition and cytotoxicity by the antioxidants $\alpha$-tocopherol and $N$-acetylcysteine. Given that TGZ also possesses antioxidant properties by virtue of its constituent $\alpha$-tocopherol moiety, a regulatory function for cellular redox status can be invoked during 4-HPR action in MCF-7 cells in the present study.

$\mathrm{N}$-(4-hydroxphenyl) retinamide induced a dose-dependent decline in cell survival, which was associated with a corresponding reciprocal dose-related increase in ceramide accumulation. Ceramide production in response to 4 -HPR was an order of magnitude greater than that observed in the presence of ATRA, again consistent with a possible receptor-independent regulation of ceramide in response to 4-HPR. One potential mediatory mechanism for this action could be via the modulation of cellular redox status and/or generation of ROS, since the antioxidant $\mathrm{N}$-acetylcysteine and the radical scavenger TGZ both reduced this ceramide response to 4-HPR. In addition, the exogenous oxidant $\mathrm{H}_{2} \mathrm{O}_{2}$ mimicked the stimulatory action of 4 - $\mathrm{HPR}$ on ceramide production. Although neutral sphingomyelinase has been previously proposed as a downstream target of oxidative stress (Andrieu-Abadie et al, 2001), we found no evidence of a role for sphingomyelin hydrolysis as a metabolic source for ceramide during 4-HPR action. Indeed, inhibition of this response to 4-HPR by $\mathrm{FB}_{1}$ and myriocin indicates a stimulatory action on the de novo synthesis pathways of ceramide production as the mechanism mediating this increase in ceramide levels. 
Despite this effective blockade of the ceramide response to 4HPR by $\mathrm{FB}_{1}$, the 4-HPR-induced decline in cell survival after $72 \mathrm{~h}$ was not prevented. Although there is thus an apparent dissociation of a mediatory role for ceramide during this action of 4-HPR, a dilemma often pertains when employing pharmacological manipulation of sphingolipid metabolism to investigate a functional role for ceramide. As essential structural and functional membrane components in growing cells, there is a continual dynamic turnover of sphingolipids as well as an ongoing requirement for their de novo synthesis. Compromising these pathways with enzyme inhibitors such as $\mathrm{FB}_{1}$ and myriocin may also lead to adverse cytotoxicity and apoptosis (Nakamura et al, 1996; Schmelz et al, 1998). Indeed, both agents induced apoptosis in MCF-7 cells in the present study while paradoxically appearing to reduce the apoptotic response to 4-HPR. Furthermore, inhibition of ceramide synthase by $\mathrm{FB}_{1}$ may lead to the accumulation of sphinganine, and other sphingoid bases, which in turn could cause inhibition of cell growth and induction of apoptosis (Schmelz et al, 1998).

The metabolic fate of endogenous ceramide production may also be subjected to pharmacological modulation. Enhanced glycosylation of ceramide by glucosylceramide synthase may contribute to multidrug resistance in cancer cells by abrogation of ceramidemediated cell death signalling (Lavie et al, 1996). In this respect, transformed cells exhibit a synergistic increase in cytotoxicity in response to 4-HPR in the presence of glucosylceramide synthase inhibitors (Nicholson et al, 1999). In the present study such an inhibitor, PDMP, did indeed enhance the decline in cell survival in response to 4-HPR. However, such findings must be interpreted with caution, since while inhibiting basal glycosylceramide production, PDMP did not modify the 4 -HPR-induced ceramide response. Furthermore, it has been recently reported that PDMP also inhibits nucleoside transport independent of ceramide production (Griner and Bollag, 2000). It thus remains equivocal as to whether glucosylceramide synthase plays a major role in modulating a putative drug-sensitive ceramide pool during 4-HPR action in MCF-7 cells. Indeed, the 4-HPR-sensitive ceramide pool appeared not to be in short-term metabolic equilibrium with that of glucosylceramide, since levels of the latter sphingolipid remained unchanged in response to 4-HPR. In contrast, under the same conditions, stimulation of de novo ceramide production in MCF-7 cells by PSC 833 led to increases in both ceramide and glycosylceramide (Cabot et al, 1998).

We have employed PSC 833, which stimulates the rate-limiting step, serine palmitoyltransferase (Wang et al, 2002), ostensibly as a positive control in the activation of de novo ceramide production. A differential mechanism of action for the stimulation of de novo ceramide synthesis by PSC 833 and 4-HPR in the present study was also evident in the qualitative and quantitative nature of the ceramide species produced; the major species produced being $\mathrm{C}_{18}$ or $\mathrm{C}_{24}$ in response to PSC 833 or 4 -HPR, respectively. The functional significance of these differences in relation to an active role for ceramide during drug-induced cytotoxicity is unknown. However, it is interesting to note that an increased accumulation of $\mathrm{C}_{24}$ ceramide was associated with a more potent loss of cell survival in response to 4-HPR vs PSC 833.

\section{REFERENCES}

Abbara A, Schrey M (2003) Cyclosporin A enhances ceramide signalling in human breast cancer cells in response to $N$-(4-hydroxyphenyl) retinamide. Endocr Abstr 6: P31

Andrieu-Abadie N, Gouaze V, Salvayre R, Levade T (2001) Ceramide in apoptosis signalling: relationship with oxidative stress. Free Radic Biol Med 31: $717-728$

Cabot M, Han T-Y, Giuliano A (1998) The multidrug resistance modulator SDZ PSC 833 is a potent activator of cellular ceramide formation. FEBS Lett 431: $185-188$
Mechanistic differences in cell signalling in response to 4-HPR and PSC 833 also include opposing actions on cellular redox. Several studies have reported the elevation of ROS in response to 4 -HPR in various cell types (Sun et al, 1999) and in this context, we have already proposed a mediatory role for oxidative stress during 4 -HPR action on ceramide production and cell survival in the present study; on the other hand, PSC 833 has been reported to suppress the generation of ROS (Nguyen et al, 1998). A role for ceramide has been recently implicated during nitric oxide-induced cell death (Rabkin, 2002) and 4-HPR is known to induce nitric oxide synthase in breast cancer cells (Simeone et al, 2002). However, in a preliminary study employing different nitric oxide synthase inhibitors, we found no evidence of a mediatory role for nitric oxide during 4-HPR-induced ceramide production in breast cancer cells (Abbara and Schrey, 2003).

The relationship of caspase activation and ceramide production with respect to 4 -HPR action is unclear. Caspase-3 may partially mediate 4-HPR-induced apoptosis in some cell types (Perry, 2000) and ceramide can activate caspase-3 (Mizushima et al, 1996); a potential mediatory role for ceramide can thus be hypothesised during drug-induced caspase activation. However, since MCF-7 cells express a mutant nonfunctional caspase- 3 due to a 47 base pair deletion in exon 3 of the CASP-3 gene (Janicke et al, 1998), such a role is unlikely in the present instance. Furthermore, in the case of caspase-3-dependent apoptosis induction by daunorubicin in lymphoblastic leukaemia cells, ceramide synthase appears to be a downstream target of caspase action (Turnbull et al, 1999). In the present study, the effect of the pancaspase inhibitor Z-VAD fmk suggests that at least $70 \%$ of the decline in MCF-7 cell survival in response to 4 -HPR is caspase-dependent. On the other hand, ceramide production in response to 4 -HPR was unaffected by $\mathrm{Z}-\mathrm{VAD}$ fmk, indicating it to be either upstream or independent of caspase activation.

Consistent with findings described above on 4-HPR action in MCF-7 cells, in the case of MDA MB 231 breast cancer cells we have recently observed a similar paradoxical differential action of both $\mathrm{FB}_{1}$ and myriocin on overall cell survival $v s$ apoptosis. Thus, the decline in cell survival in response to 4 -HPR after $72 \mathrm{~h}$ is unaffected by blockade of ceramide production, whereas apoptosis monitored after $24 \mathrm{~h}$ is partially prevented (Abbara and Schrey, 2003). Such observations illustrate the complex manifold actions of 4-HPR, which may cause cell death by mixed apoptosis/necrosis by both caspase-dependent and -independent pathways (DiPietrantonio et al, 1998; Maurer et al, 1999). Indeed, in contrast to the caspase-dependent nature of 4-HPR action on MCF-7 survival described in the present study, caspase activation was not required for 4-HPR-induced cytotoxicity in MDA MB 231 cells (unpublished observations).

The present study describes a novel redox-sensitive stimulation of ceramide production in breast cancer cells by 4-HPR. Although elevation of this sphingolipid is associated with the cytotoxic action of 4-HPR, a major mediatory role for ceramide in this context remains equivocal. Our findings also highlight a need for caution when interpreting a functional role for ceramide signalling during 4-HPR action, when it is based on the effects of putative modulators of ceramide metabolism.
Dawson M, Chao W, Pine P, Jong L, Hobbs P, Rudd C, Quick T, Niles R, Zhang X, Lombardo A, Ely R, Shroot B, Fontana J (1995) Correlation of retinoid binding affinity to retinoic acid receptor alpha with retinoid inhibition of growth of oestrogen receptor-positive MCF-7 mammary carcinoma cells. Cancer Res 55: 4446-4451

Decensi A, Bonanni B, Guerrieri-Gonzaga A, Torrisi R, Manetti L, Robertson C, DePalo G, Formelli F, Costa A, Veronesi U (2000) Chemoprevention of breast cancer: the Italian experience. J Cell Biochem 77: $84-96$ 
DiPietrantonio A, Hsieh T-C, Olson S, Wu J (1998) Regulation of $\mathrm{G}_{1} / \mathrm{S}$ transition and induction of apoptosis in HL-60 leukaemia cells by fenretinide (4HPR). Int J Cancer 78: 53-61

Elstner E, Muller C, Koshizuka K, Williamson E, Park D, Asou H, Shintaku P, Said J, Heber D, Koeffler H (1998) Ligands for peroxisome proliferator-activated receptor $\gamma$ and retinoic acid receptor inhibit growth and induce apoptosis of human breast cancer cells in vitro and in BNX mice. Proc Natl Acad Sci USA 95: 8806-8811

Griner R, Bollag W (2000) Inhibition of ${ }^{3} \mathrm{H}$-thymidine transport is a nonspecific effect of PDMP in primary cultures of mouse epidermal keratinocytes. J Pharmacol Exp Ther 294: 1219-1224

James S, Lin F, Kolluri S, Dawson M, Zhang X-K (2003) Regulation of retinoic acid receptor $\beta$ expression by peroxisome proliferator-activated receptor $\gamma$ ligands in cancer cells. Cancer Res 63: 3531-3538

Janicke R, Sprengart M, Wati M, Porter A (1998) Caspase-3 is required for DNA fragmentation and morphological changes associated with apoptosis. J Biol Chem 273: 9357-9360

Lavie Y, Cao H, Bursten S, Giuliano A, Cabot M (1996) Accumulation of glucosylceramides in multi drug-resistant cancer cells. J Biol Chem 271: $19530-19536$

Maurer B, Metelitsa L, Seeger R, Cabot M, Reynolds C (1999) Increase of ceramide and induction of mixed apoptosis/necrosis by $\mathrm{N}$-(4-hydroxyphenyl) retinamide in neuroblastoma cell lines. J Natl Cancer Inst 91: $1138-1146$

Miguet C, Monier S, Bettaieb A, Athias A, Bessede G, Laubriet A, Lemaire S, Neel D, Gambert P, Lizard G (2001) Ceramide generation occurring during 7-beta-hydroxycholesterol and 7-ketocholesterol-induced apoptosis is caspase independent and is not required to trigger cell death. Cell Death Differ 8: 83-99

Mizushima N, Koike R, Kohsaka H, Kushi Y, Handa S, Yagita H, Miyasaka $\mathrm{N}$ (1996) Ceramide induces apoptosis via CPP 32 activation. FEBS Lett 395: $267-271$

Nagy B, Chiu S, Separovic D (2000) Fumonisin $B_{1}$ does not prevent apoptosis in A431 human epidermoid carcinoma cells after photosensitization with a silicon phthalocyanine. J Photochem Photobiol B 57: $132-141$

Nakamura S, Kozutsumi Y, Sun Y, Miyake Y, Fujita T, Kawasaki T (1996) Dual role of sphingolipids in signalling of the escape from and onset of apoptosis in a mouse cytotoxic T-cell line, CTLL-2. J Biol Chem 271: $1255-1257$

Nguyen N, Pulido S, Ruegg U (1998) Biphasic effects of cyclosporin A on formyl-methionyl-leucyl-phenylalanine stimulated responses in HL-60 cells differentiated into neutrophils. Br J Pharmacol 124: 1774-1780

Nicholson K, Quinn D, Kellett G, Warr J (1999) Preferential killing of multidrug-resistant $\mathrm{KB}$ cells by inhibitors of glucosylceramide synthase. Br J Cancer 81: 423 - 430

Oridate N, Lotan D, Xu X, Hong W, Lotan R (1996) Differential induction of apoptosis by all-trans-retinoic acid and $\mathrm{N}$-(4-hydroxyphenyl) retinamide in human head and neck squamous cell carcinoma cell lines. Clin Cancer Res 2: $855-863$
Perry D (2000) The role of de novo ceramide synthesis in chemotherapy induced apoptosis. Ann NY Acad Sci 905: 91-96

Rabkin S (2002) Fumonisin blunts nitric oxide-induced and nitroprussideinduced cardiomyocyte death. Nitric Oxide 7: 229-235

Schmelz E, Dombrink-Kurtzman M, Roberts P, Kozutsumi Y, Kawasaki T, Merrill Jr AJ (1998) Induction of apoptosis by fumonisin $B_{1}$ in HT29 cells is mediated by the accummulation of endogenous free sphingoid bases. Toxicol Appl Pharmacol 148: $252-260$

Schulman I, Shao G, Heyman R (1998) Transactivation by retinoid X receptor-peroxisome proliferator activated receptor gamma (PPAR $\gamma)$ heterodimers: Intermolecular synergy requires only the PPAR $\gamma$-dependent activation function. Mol Cell Biol 18: 3483-3494

Sheikh M, Shao Z, Li X, Ordonez J, Conley B, Wu S, Dawson M, Han Q, Chao W, Quick T, Niles R, Fontana J (1995) N-(4-hydroxyphenyl) retinamide (4HPR)-mediated biological actions involve retinoid receptor-independent pathways in human breast carcinoma. Carcinogenesis 16: $2477-2486$

Simeone A-M, Ekmekcioglu S, Broemeling L, Grimm E, Tari A (2002) A novel mechanism by which $N$-(4-hydroxyphenyl) retinamide inhibits breast cancer cell growth: the production of nitric oxide. Mol Cancer Therap 1: 1009-1017

Stoll B (2002) Linkage between retinoid and fatty acid receptors: implications for breast cancer prevention. Eur J Cancer Prev 11: 319-325

Sun S-Y, Li W, Yue P, Lippman S, Hong W, Lotan R (1999) Mediation of N(4-hydroxyphenyl) retinamide-induced apoptosis in human cancer cells by different mechanisms. Cancer Res 59: 2493-2498

Suzuki S, Higuchi M, Proske R, Oridate N, Hong W, Lotan R (1999) Implication of mitochondria-derived reactive oxygen species, cytochrome $\mathrm{C}$ release and caspase-3 in $N$-(4-hydroxyphenyl) retinamide-induced apoptosis in cervical carcinoma cells. Oncogene 18: $6380-6387$

Turnbull K, Brown B, Dobson P (1999) Caspase-3 activity is necessary but not sufficient for daunorubicin-induced apoptosis in Jurkat human lymphoblastic leukemia cells. Leukemia 13: $1056-1061$

Ulukaya E, Wood E (1999) Fenretinide and its relation to cancer. Cancer Treat Rev 25: 229-235

Veronesi U, DePalo G, Marubini E, Costa A, Formelli F, Mariani L, Decensi A, Camerini T, DelTurco M, DiMauro M, Muraca M, Vecchio MD, Pinto C, D’Aiuto G, Boni C, Campa T, Magni A, Miceli R, Perloff M, Malone W, Sporn M (1999) Randomized trial of fenretinide to prevent second breast malignancy in women with early breast cancer. J Natl Cancer Inst 91: $1847-1856$

Wang H, Giuliano A, Cabot M (2002) Enhanced de novo ceramide generation through activation of serine palmitoyltransferase by the P-glycoprotein antagonist SDZ PSC 833 in breast cancer cells. Mol Cancer Ther 1: 719-726

Zou C, Kurie J, Lotan D, Zou C, Hong W, Lotan R (1998) Higher potency of $\mathrm{N}$-(4-hydroxyphenyl) retinamide than all-trans-retinoic acid in induction of apoptosis in non-small cell lung cancer cell lines. Clin Cancer Res 4: $1345-1355$ 